\title{
Theoretical Studies of Physical, Chemical, and Vibrational Properties of Various Imidazolium-Based Ionic Liquids
}

\author{
S.K. GuPta ${ }^{a}$, A.K. GUPtA ${ }^{a, *}$ And R.K. YADAV ${ }^{b}$ \\ ${ }^{a}$ Nanoionics and Energy Storage Laboratory (NanoESL), \\ Department of Physics and Material Science, \\ Madan Mohan Malaviya University of Technology, Gorakhpur (U.P.), 273010, India \\ ${ }^{b}$ Department of Chemical and Environmental Science, \\ Madan Mohan Malaviya University of Technology, Gorakhpur (U.P.), 273010, India
}

Received: 19.07.2021 \& Accepted: 08.11.2021

Doi: 10.12693/APhysPolA.140.400

*e-mail: akgupta.mmmut@gmail.com

\begin{abstract}
In the present paper, inter-ionic reactions involving two cations and four anions were used to model the formation of neutral ion pairs. Moreover, density functional theory technique has been used to describe the physical, chemical, and vibrational properties of the ionic liquids, containing imidazolium-based cations and different anions at functional B3LYP with a def2-SVP basis set. The chemical parameters have been investigated for different ionic liquids along with frontier orbitals "highest occupied molecular orbital" and "lowest unoccupied molecular orbital" studies. All the optimized structures of the ionic liquids did not produce imaginary frequency (i.e., imaginary frequency is zero), which validates that the structures are energetically stable. The density functional theory method provides the stability sequence for ionic liquids: $\left[\mathrm{BMIM}^{2}\left[\mathrm{PF}_{6}\right]>[\mathrm{EMIM}]\left[\mathrm{PF}_{6}\right]>[\mathrm{BMIM}][\right.$ TFSI $]>[$ EMIM $][$ TFSI $]>[\mathrm{EMIM}][\mathrm{Cl}]>$ $[\mathrm{BMIM}][\mathrm{Cl}]>[\mathrm{EMIM}][\mathrm{Br}]>[\mathrm{BMIM}][\mathrm{Br}]$. Herein, $[\mathrm{BMIM}][\mathrm{PF} 6]$ ionic liquid has highest energy gap $(4.833 \mathrm{eV})$ that means that [BMIM][PF6] is the most stable.
\end{abstract}

topics: DFT, HOMO-LUMO gap, ionic liquids, electrochemical potential window

\section{Introduction}

Ionic liquids (ILs) have been studied for nearly a century. Recently, however, they have gained interest, owing to their potential as an eco-friendly alternative to organic solvents [1-3]. Due to the increasing number of publications on ionic liquids in the last two decades, the theoretical calculations of ILs has gained attention [3-7]. Solvents for heterogeneous and homogeneous catalysis, discerning solvents for substantial metal contamination removal, electrolytes in energy storage systems, and diffusing agents for nanoparticle stabilization are all examples of IL applications [1]. Undoubtedly, the ecofriendliness and low vapor pressure, i.e., properties of ionic liquid, open its vast potential applications and boost the curiosity of researchers. Recently, ionic liquids have remained the centre of the study of researchers due to their potential and technical applications $[5,8]$. The ILs have a largeelectrochemical window, excellent electrical conductivity, low melting point, large thermal and chemical stability. It can be tuned as per the suitability and choice of cations-anions $[9,10]$. The ILs are predicted as "green solvent" because of their negligible vapor pressure which supports the negligible loss of solvent to the environment $[2,11]$. Ionic liquid systems consist of organic cations (as $\mathrm{EMIM}^{+}, \mathrm{BMIM}^{+}, \mathrm{HMIM}^{+}$and $\mathrm{OMIM}^{+}$etc.) and inorganic anions (as $\mathrm{PF}_{6}^{-}, \mathrm{BF}_{4}^{-}, \mathrm{Cl}^{-}, \mathrm{Br}^{-}, \mathrm{DCA}^{-}$ and TFSI $^{-}$etc.) $[6,12]$.

Moreover, ILs based on imidazolium have attracted a lot of attention. Imidazolium-based ILs are one of the most studied ionic liquids in the literature, with the number of publications on the subject growing at an exponential rate. Imidazoliumbased ILs are nitrogen-rich heteroatoms having a low melting point, excellent chemical stability, and excellent ionization capability. Because of the stable positive charge position of the aromatic ring, which acts as a versatile cation framework for the ILs, the use of imidazolium as a cation structure is an attractive molecular strategy [13, 14]. Because of its distinctive low viscosity, low melting temperatures, ease of preparation, and great stability under oxidative and reductive conditions, it can be employed in polymer synthesis, energy storage, solvent, catalysis, biofuel production, sensing, heat transport 
and storage, analytical chemistry, and tribology etc. $[15,16]$. However, there was relatively little information on properties of imidazolium-based ILs in the literature.

The ILs have been classified by the researchers into several classes, but in the present manuscript imidazolium-based ionic liquids have been investigated as energy storage applications and toxic materials removal agents. The DFT method is widely used to compute the various structural, electronic, thermal, and vibrational behaviors of ILs. This article is focused on the calculation of chemical parameters, highest occupied molecular orbital and lowest unoccupied molecular orbital (HOMO-LUMO) energy level, cations-anions interactions, and vibrational studies of ILs. The electrochemical potential windows (ECWs) are one of the most essential parameters of electrochemical energy storage devices. The ECWs have been investigated for different ILs using the HOMO-LUMO measurement technique. The molecular orbital theory (MOT) is a powerful approach to calculating and analyzing the reactivity and stability of molecules. In quantum chemistry, there are several important parameters that include HOMO and LUMO energies, energy gap $\left(\Delta E_{\text {gap }}\right)$, electronegativity $(\chi)$, chemical potential $(\mu)$, chemical hardness $(\eta)$, softness $(S)$, and electrophilicity index $(\omega)$ that define the properties of materials and their potential application.

\section{Computational details}

A fully extended molecule of ILs was used as an initial configuration for simulation in the present study. The initial configurations have been drawn using Avogadro software based on the previously reported structures through several literature $[3,6,15,17]$. Herein, different basis sets were considered for geometry optimization to find an appropriate one. Finally, the structure of ionic liquids was optimized using hybrid functional (B3LYP) [18] with a valence double-zeta (def2-SVP) basis set. This basis set is a diffuse function that ensures high accuracy to the calculation. The zero value of imaginary frequency in the output confirmed that the relaxed structure obtained was completely optimized and has attained its lowest energy level. Hence, the ILs optimized in present study are found energetically stable. Furthermore, vibrational studies were carried out on optimized structures. All calculations were performed using the ORCA 4.1.0 program [19].

From MOT perspectives, HOMO has the capacity to donate an electron while LUMO accepts the electron [6]. HOMO-LUMO levels of ionic liquids were obtained from Iboview. By Koopman's theorem, the HOMO energy $\left(E_{\mathrm{HOMO}}\right)$ is associated with ionization potential (IP) and nearly related position of the electrophilic attack. The LUMO energy $\left(E_{\mathrm{LUMO}}\right)$, in turn, is closely related position of the nucleophilic attack [20-22] and was taken to compute electron affinity (EA). The differences between the HOMO and LUMO energy value provide an energy gap $\left(\Delta E_{\text {gap }}\right)$ which is investigated by the following expression

$$
E_{\mathrm{LUMO}}-E_{\mathrm{HOMO}}=\Delta E_{\text {gap }} .
$$

Quantum molecular descriptor like chemical hardness $(\eta)$, chemical softness $(S)$, electronegativity $(\chi)$ represent the capacity of molecules to attract electrons to itself. Chemical potential $(\mu)$ is the main indicator of any molecular reactivity and the most basic descriptor of charge transfer during a chemical reaction. The electrophilic index $(\omega)$ consists of information related to the structural and reactivity pattern of several electron systems in the ground and excited state [23-25].

Large ECWs in ILs are suitable for improving the energy and power density of energy storage devices [26]. The voltage range between which the electrolyte is neither oxidized nor reduced is referred to as the ECW of ILs. The electrochemical stability of ionic liquids can be investigated by the simplest method in which the LUMO energy is correlated with the cathodic stability while the HOMO energy value with the anodic stability. These are calculated by the following expressions [16, 27] (anodic limit $V_{\mathrm{al}}$, cathodic limit $V_{\mathrm{cl}}$ )

$$
\begin{aligned}
& V_{\mathrm{al}}=-\frac{E_{\mathrm{HOMO}}}{e}, \\
& V_{\mathrm{cl}}=-\frac{E_{\mathrm{LUMO}}}{e},
\end{aligned}
$$

electrochemical window $=V_{\mathrm{al}}-V_{\mathrm{cl}}$,

where $e$ is the charge of an electron. One of the most significant quality to look for in electrolytes for electrochemical applications is ECW. It is worth noting that chemical processes on the surface of electrodes are indistinguishably linked to electron transfer. The electrochemical stability windows of ILs are determined by the combined effect of the alkyl chain of the imidazolium rings $[16,27]$. The experimental potential windows cannot be quantitatively reproduced because the theoretical technique utilized in this study does not account for the effects of solvation or the environment on the electrochemical stability of ILs.

Understanding the nature of intermolecular forces is required to comprehend material characteristics. They determine whether matter adheres to one another, whether gases condense into liquids and whether liquids freeze into solids. Ionic liquids are particularly interesting material because of the force which holds the cationic and anionic component of IL in amazing way that endows IL with versatile properties. The extraordinarily low vapor pressures and high enthalpies of vaporization in these Coulomb fluids reflect the strong anioncation interaction. In ionic liquids, measuring the interaction energy between cation and anion remains a difficult task $[1,28]$. In particular, the interaction energies in ILs are worth mentioning. The interaction energy $\left(\Delta E_{\text {int }}\right)$ was calculated using

$$
\Delta E_{\text {int }}=E_{\mathrm{IL}}-\left(E_{\text {cation }}+E_{\text {anion }}\right),
$$


where $E_{\mathrm{IL}}$ signifies to the total energy of ILs while $E_{\text {cation }}$ and $E_{\text {anion }}$ are carried as energies of cationic and anionic part, respectively [27]. The IR spectra of ILs were also studied using density functional techniques.

\section{Result and discussion}

\subsection{Quantum molecular descriptors}

Optimized structure of cations-anions and ILs with the distribution of HOMO and LUMO are shown in Figs. 1 and 2, respectively. The chemical parameters of molecules were described by HOMO and LUMO energy values. If the energy of HOMO is low, that implies high ionization potential. If the energy of LUMO is high, that implies high electron affinity $[3,6,15,27]$. Figure 1 shows that HOMO for cations is concentrated mainly on imidazolium rings which signifies that $[\mathrm{EMIM}]^{+}$will be better electron donor than $[\mathrm{BMIM}]^{+}[27]$. Hence, $[\mathrm{EMIM}]^{+}$based IL will be more stable. For anions HOMO is almost distributed all over the surface. Furthermore, LUMO of $[\mathrm{TFSI}]^{-}$and $\left[\mathrm{PF}_{6}\right]^{-}$anions more concentrated on electronegative atoms, nitrogen $(\mathrm{N})$ and fluorine $(\mathrm{F})$.

Figure 2 shows that HOMO for ILs are mostly directed on anions. The anion states are always dominant in HOMO, implying that the anion controls the anodic stability. This confirms that anions play important role in the ion dynamics of the electrolytes for energy storage applications [6]. LUMO is strongly located within the imidazolium ring and halogen (i.e., more electronegative) atoms like chlorine $(\mathrm{Cl})$ and bromine $(\mathrm{Br})[3,15]$.

The values of ionization potential, electron affinity, and HOMO-LUMO gap $\left(\Delta E_{\text {gap }}\right)$ were calculated and given in Table I. It should be noted that values of computational study parameters mainly depend on the exchange-correlation functional and (a)

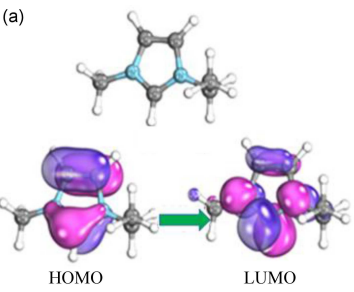

(c)
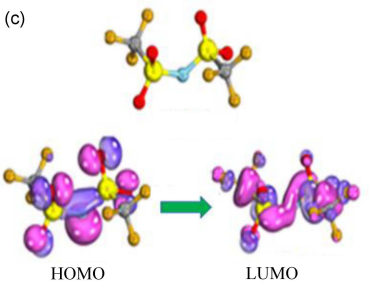

(b)

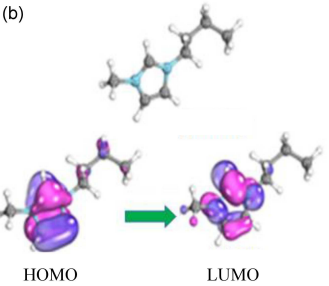

(d)
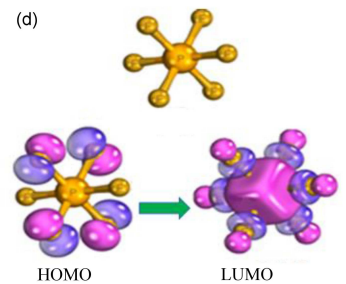

Fig. 1. Optimized structures and orbital plots of cations (a) $[\mathrm{EMIM}]^{+}$and (b) $[\mathrm{BMIM}]^{+}$, and anions (c) $[\mathrm{TFSI}]^{-}$and (d) $\left[\mathrm{PF}_{6}\right]^{-}$at $\mathrm{DFT} / \mathrm{B} 3 \mathrm{LYP} /$ def2SVP level.

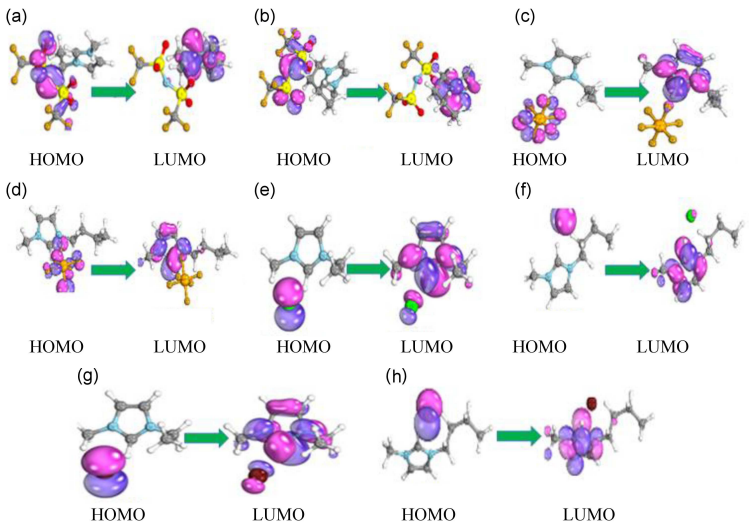

Fig. 2. The optimized structure and molecular orbital plots of the ILs at contour 0.02 a.u. (for HOMO and LUMO surface) using DFT/B3LYP/def2-SVP level (a) [EMIM][TFSI], (b) $\quad[\mathrm{BMIM}][\mathrm{TFSI}], \quad$ (c) $[\mathrm{EMIM}]\left[\mathrm{PF}_{6}\right], \quad$ (d) $[\mathrm{BMIM}]\left[\mathrm{PF}_{6}\right]$, (e) [EMIM] $[\mathrm{Cl}]$, (f) [BMIM][Cl], (g) $[\mathrm{EMIM}][\mathrm{Br}]$, and $(\mathrm{h})[\mathrm{BMIM}][\mathrm{Br}]$.

TABLE I

Ionization potential (IP), electron affinity (EA), and HOMO-LUMO gap ( $\left.\Delta E_{\text {gap }}\right)$ of ILs calculated at DFT/B3LYP/def2-SVP level including previously stated theoretical and experimental values of $\Delta E_{\text {gap }}$.

\begin{tabular}{|c|c|c|c|c|}
\hline System & $\mathrm{IP}[\mathrm{eV}]$ & $\mathrm{EA}[\mathrm{eV}]$ & $\begin{array}{c}\Delta E_{\text {gap }} \\
{[\mathrm{eV}]}\end{array}$ & $\begin{array}{c}\text { Literature } \\
\Delta E_{\text {gap }}[\mathrm{eV}]\end{array}$ \\
\hline [TFSI] $^{-}$ & 5.916 & 2.170 & 6.012 & $4.100^{a}$ \\
\hline$\left[\mathrm{PF}_{6}\right]^{-}$ & 6.279 & 1.515 & 12.080 & $16.218^{b}$ \\
\hline 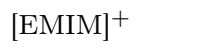 & 6.976 & 2.175 & 6.765 & $3.420^{a}$ \\
\hline$[\mathrm{BMIM}]^{+}$ & 4.072 & 1.753 & 6.733 & $8.160^{b}$ \\
\hline [EMIM][TFSI] & 5.971 & 2.186 & 3.746 & $4.280^{c}, 5.84^{d}$ \\
\hline [BMIM][TFSI] & 3.974 & 1.596 & 3.785 & $3.25^{d}, 4.300^{e}$ \\
\hline$[\mathrm{EMIM}]\left[\mathrm{PF}_{6}\right]$ & 5.581 & 2.432 & 4.801 & - \\
\hline$[\mathrm{BMIM}]\left[\mathrm{PF}_{6}\right]$ & 4.143 & 1.149 & 4.833 & $4.39^{f}$ \\
\hline [EMIM][Cl] & 3.827 & 1.804 & 2.644 & - \\
\hline$[\mathrm{BMIM}][\mathrm{Cl}]$ & 3.973 & 1.595 & 2.378 & - \\
\hline [EMIM][Br] & 6.987 & 2.154 & 2.319 & - \\
\hline [BMIM] $[\mathrm{Br}]$ & 3.827 & 1.805 & 2.023 & - \\
\hline
\end{tabular}

theoretical: ${ }^{a}$ Ref. [6], ${ }^{b}$ Ref. [31], ${ }^{d}$ Ref. [32], ${ }^{f}$ Ref. [10]; experimental: ${ }^{c}$ Ref. [6], ${ }^{e}$ Ref. [32]

basis sets. For different exchange-correlation functional and basis sets the values of calculated parameters will be different. From calculation, cations $[\mathrm{EMIM}]^{+}$, and $[\mathrm{BMIM}]^{+}$possessed HOMO energies as follows -11.820 , and $-11.698 \mathrm{eV}$, respectively, and anions $[\mathrm{TFSI}]^{-}$, and $\left[\mathrm{PF}_{6}\right]^{-}$possessed HOMO energies as -2.491 , and $-4.375 \mathrm{eV}$, respectively $[17,21]$. The order of HOMO energy value between these cations are as in order $[\mathrm{EMIM}]^{+}>$ $[\mathrm{BMIM}]^{+}$.

In ILs, it was observed that $[\mathrm{EMIM}]\left[\mathrm{PF}_{6}\right]$ and $[\mathrm{BMIM}]\left[\mathrm{PF}_{6}\right]$ have the highest HOMO energy value $(-6.987$ and $-6.976 \mathrm{eV})$ which implies that the 
stability of these ILs is low and reactivity high. Therefore, $[\mathrm{EMIM}]\left[\mathrm{PF}_{6}\right]$ and $[\mathrm{BMIM}]\left[\mathrm{PF}_{6}\right]$ are recognized as the most useful ionic liquids for energy storage applications $[6,15,29]$. The DFT method provides the stability row for ionic liquids: $[\mathrm{BMIM}][\mathrm{PF} 6]>[\mathrm{EMIM}][\mathrm{PF} 6]>[\mathrm{BMIM}][$ TFSI $]$ $>[\mathrm{EMIM}][\mathrm{TFSI}]>[\mathrm{EMIM}][\mathrm{Cl}]>[\mathrm{BMIM}][\mathrm{Cl}]>$ $[\mathrm{EMIM}][\mathrm{Br}]>[\mathrm{BMIM}][\mathrm{Br}][5,6,15,16,21,29,30]$. Comparisons with the previous computational/ experimental studies have been given in Table I.

[BMIM] [Br] has a lower energy gap value $(2.023 \mathrm{eV})$ which means that [BMIM] [Br] is more reactive but less stable. [BMIM] $\left[\mathrm{PF}_{6}\right]$ has higher energy gap $(4.833 \mathrm{eV})$ that means $[\mathrm{BMIM}]\left[\mathrm{PF}_{6}\right]$ is more stable. A large HOMO-LUMO energy gap implies that molecules are hard which is why opposing charge transfer. Furthermore, having small HOMO-LUMO energy gap molecules implies soft molecules [30]. In the case of cations, $[\mathrm{EMIM}]^{+}$has lowest chemical softness value $\left(0.296 \mathrm{eV}^{-1}\right)$. For the removal of heavy metals, the better ILs would be the ones whose complex has a large softness value. Therefore, $[\mathrm{BMIM}][\mathrm{Br}]$ is taken as the appropriate ionic liquid for shifting toxic wastes [33-35]. The value of electronegativity and electrophilicity index are reported in Table II. Out of eight ILs which were investigated, [EMIM] $\left[\mathrm{PF}_{6}\right]$ was found most electronegative. Herein, we also conclude that all cations have high electronegative values compared to the anions. From Table II, cations have a large electrophilicity index value compared to anions. Cation $[\mathrm{EMIM}]^{+}$has high electrophilic index value $(10.520 \mathrm{eV})$ which implies the best electron acceptor followed by $[\mathrm{BMIM}]^{+}[24,25]$. In ILs, [BMIM][TFSI] has a high electrophilic index value $(4.395 \mathrm{eV})$ which implies that the nucleophilicity can donate electrons and the electrophilic can accept electrons in an ionic liquid. Hence, [BMIM] [TFSI] is one of the best ionic liquid for extraction of toxic waste $[34,35]$.

\section{TABLE II}

The computed values of chemical parameters of cations-anions, and their combination of ILs at DFT/B3LYP/def2-SVP level.

\begin{tabular}{|c|c|c|c|c|c|}
\hline System & $\chi[\mathrm{eV}]$ & $\mu[\mathrm{eV}]$ & $\eta[\mathrm{eV}]$ & $S\left[\mathrm{eV}^{-1}\right]$ & $\omega[\mathrm{eV}]$ \\
\hline [TFSI $^{-}$ & -0.515 & 0.515 & 3.006 & 0.333 & 0.044 \\
\hline$\left[\mathrm{PF}_{6}\right]^{-}$ & -3.333 & 3.333 & 6.041 & 0.165 & 0.919 \\
\hline$[\mathrm{EMIM}]^{+}$ & 8.437 & -8.437 & 3.382 & 0.296 & 10.520 \\
\hline$\left.{ }_{[\mathrm{BMIM}}\right]^{+}$ & 8.332 & -8.332 & 3.366 & 0.297 & 10.310 \\
\hline [EMIM][TFSI] & 4.043 & -4.043 & 1.873 & 0.534 & 4.363 \\
\hline [BMIM][TFSI] & 4.078 & -4.078 & 1.892 & 0.528 & 4.395 \\
\hline$[\mathrm{EMIM}]\left[\mathrm{PF}_{6}\right]$ & 4.575 & -4.575 & 2.401 & 0.416 & 4.359 \\
\hline$[\mathrm{BMIM}]\left[\mathrm{PF}_{6}\right]$ & 4.570 & -4.570 & 2.416 & 0.414 & 4.322 \\
\hline [EMIM][Cl] & 2.882 & -2.882 & 1.322 & 0.756 & 3.141 \\
\hline [BMIM] $][\mathrm{Cl}]$ & 2.785 & -2.785 & 1.189 & 0.841 & 3.262 \\
\hline [EMIM][Br] & 2.912 & -2.912 & 1.159 & 0.863 & 3.658 \\
\hline [BMIM][Br] & 2.816 & -2.816 & 1.012 & 0.988 & 3.918 \\
\hline
\end{tabular}

3.2. Interaction energy and electrochemical stability, i.e., ECW by HOMO-LUMO method

To evaluate interaction energies $\left(\Delta E_{\text {int }}\right)$, the single point calculation at DFT/B3LYP/def2-SVP was taken out and aware about the basis set superposition errors. The interaction energy values of ILs are given in Table III. We observed the inter-

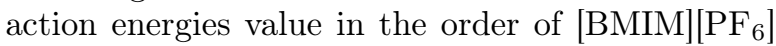
$>[\mathrm{EMIM}]\left[\mathrm{PF}_{6}\right]>[\mathrm{BMIM}][\mathrm{Cl}]>[\mathrm{BMIM}][\mathrm{Br}]>$ $[$ EMIM $][\mathrm{Cl}]>[\mathrm{BMIM}][$ TFSI $]>[$ EMIM $][\mathrm{Br}]>$ [EMIM][TFSI].

Table III shows all the imidazolium ionic liquids which were taken under study, have negative interaction energy values. Interaction energies between a cation and an anion for ILs are typically in the range of -1 to $-3 \mathrm{~kJ} / \mathrm{mol}$. Positive values mean that not attractive but repulsive interactions are dominant, which indicates that the studied structure of interest is not stable. If the value of interaction energy is positive, this implies a stronger bond within the isolated molecules of cations and anions, while the negative value of interaction energy signifies interaction between cations and anions [25]. [BMIM] $\left[\mathrm{PF}_{6}\right]$ has the favorable interaction within cation and anions among ILs discussed here $(-2.904 \mathrm{~kJ} / \mathrm{mol})$. The ability of the cation-anion interaction also affects the kinetic behaviors of organic reactions [36].

The ECWs of ILs play a crucial role when used in energy storage devices. The requirement for electrolytes in the high-voltage application should have large ECWs, excellent thermal stability, low vapor pressure, and a wide liquid range $[10,16,26,27]$. The ECW is one of the most important parameters of ILs. Many ILs having the value of ECW in the range of 4-7 $\mathrm{V}[10]$. Furthermore, the ECWs by the HOMO-LUMO method can be investigated by oxidation and reduction potential (anodic and cathodic limits). The values of ECWs of ILs were calculated using (2)-(4) respectively and presented

TABLE III

Interaction energies and ECWs values of ILs, calculated at DFT/B3LYP/def2-SVP level. Designations: $\mathrm{N}$ - name of ionic liquids, $\Delta E$ - interaction energy difference of cation-anion, $V_{\mathrm{al}}$ - anodic limit (oxidation potential), $V_{\mathrm{cl}}$ - cathodic limit (reduction potential), ECWs calculated with HOMO-LUMO method.

\begin{tabular}{l|c|c|c|c}
\hline \hline \multicolumn{1}{c|}{$\mathrm{N}$} & $\Delta E[\mathrm{~kJ} / \mathrm{mol}]$ & $V_{\mathrm{al}}[\mathrm{V}]$ & $V_{\mathrm{cl}}[\mathrm{V}]$ & ECWs $[\mathrm{V}]$ \\
\hline [EMIM][TFSI] & -1.483 & 5.916 & 2.170 & 3.746 \\
[BMIM][TFSI] & -1.700 & 5.971 & 2.186 & 3.785 \\
[EMIM][PF 6$]$ & -2.753 & 6.976 & 2.175 & 4.801 \\
[BMIM][PF 6$]$ & -2.904 & 6.987 & 2.154 & 4.833 \\
[EMIM][Cl] & -1.716 & 4.204 & 1.560 & 2.644 \\
[BMIM][Cl] & -1.853 & 3.974 & 1.596 & 2.378 \\
[EMIM][Br] & -1.613 & 4.072 & 1.753 & 2.319 \\
[BMIM][Br] & -1.827 & 3.827 & 1.804 & 2.023
\end{tabular}




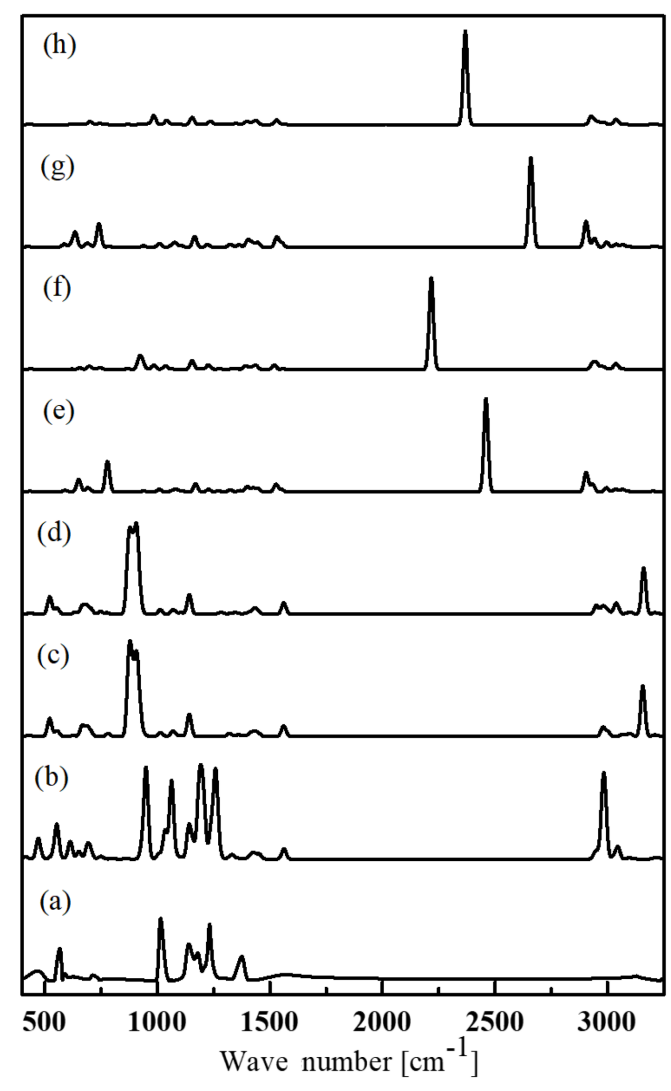

Fig. 3. IR spectra of (a) [EMIM][TFSI], (b)

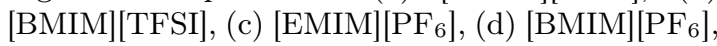
(e) $[\mathrm{EMIM}][\mathrm{Cl}]$, (f) $[\mathrm{BMIM}][\mathrm{Cl}]$, (g) $[\mathrm{EMIM}][\mathrm{Br}]$, and $(\mathrm{h})[\mathrm{BMIM}][\mathrm{Br}]$ ionic liquids investigated at DFT/B3LYP/def2-SVP level.

in Table III. The phenomenon of the transfer of electrons from the highest energy levels of the molecules is called the oxidation reaction. Therefore, if the molecules or ions have small HOMO energies, it shows higher oxidation potential [10]. Herein, in the case of anions, TFSI shows the smallest HOMO energy value and consequently, this has the highest oxidation potential. From Table III, we observed that ionic liquid $[\mathrm{BMIM}]\left[\mathrm{PF}_{6}\right]$ has the largest electrochemical stability window $(4.833 \mathrm{~V})$ among all the imidazolium-based ionic liquids, while $[\mathrm{BMIM}][\mathrm{Br}]$ have the lowest electrochemical stability window $(2.023 \mathrm{~V})$. More chemically stable molecules have larger HOMO-LUMO energy gap which makes it ideal for use as an electrolyte in different energy storage applications [6].

\subsection{Study of vibrational spectra}

The infrared spectra give strong information about the functional groups, especially hydrogenbonded interactions, and constitution difference of the organic cations in distinct ILs. The IR-spectra of imidazolium-based ILs are presented in Fig. 3. The IR absorption spectra profile of all the ILs is very different due to its anions.
For the IR absorption profile of [EMIM][TFSI], its spectrum is strongly dominated by contributions from the $[\text { TFSI }]^{-}$anion. Mostly all modes are found in the mid-frequency range. The interaction between the imidazolium ring of the cationic and anionic fragment is responsible for the most intense peak at $1070 \mathrm{~cm}^{-1}[5,6,11]$. Stretching $\mathrm{S}=\mathrm{O}$ bonds is represented by the band at $1250 \mathrm{~cm}^{-1}$. In the anion and molecule spectra, the intense peaks at 1070 and $1180 \mathrm{~cm}^{-1}$ correspond to the S-N-S, $\mathrm{S}=\mathrm{O}$, and $\mathrm{N}-\mathrm{S}-\mathrm{C}$ stretching vibrations. Three anion peaks $\left(485,575\right.$, and $\left.634 \mathrm{~cm}^{-1}\right)$ are combined in the low-frequency domain to form a broad band at $584 \mathrm{~cm}^{-1}$ (S-N oscillation) in the ion pair. The peaks at $546 \mathrm{~cm}^{-1}$ are due to $\mathrm{CF}_{3}$ asymmetric bending. A strong $\mathrm{C}-\mathrm{C}$ stretching is observed at $1191 \mathrm{~cm}^{-1}$, though anion is dominating between 1500 and $1350 \mathrm{~cm}^{-1}$ again. The $\mathrm{CF}_{3}$ asymmetric stretching at 1149 and $1203 \mathrm{~cm}^{-1}$ and $\mathrm{CF}_{3}$ symmetric stretching at $1260 \mathrm{~cm}^{-1}$ occur. Only the vibrations of the cation portion are observed in the high frequency area. At $3180 \mathrm{~cm}^{-1}$, which confirms the stretching $\mathrm{C}-\mathrm{H}$ mode of the methyl group of the imidazolium ring.

For the IR absorption profile of [BMIM][TFSI], the spectrum is strongly dominated by contributions from the [TFSI $^{-}$anion. The peaks at $546 \mathrm{~cm}^{-1}$ are due to $\mathrm{CF}_{3}$ asymmetric bending, $620 \mathrm{~cm}^{-1}$ due to $\mathrm{SO}_{2}$ asymmetric bending, S-N-S bending at $683 \mathrm{~cm}^{-1}$, and a strong C-C stretching at $1191 \mathrm{~cm}^{-1}$, though anion is dominating between 1800 and $1350 \mathrm{~cm}^{-1}$ again. The $\mathrm{CF}_{3}$ asymmetric stretching at 1149 and $1203 \mathrm{~cm}^{-1}$ and a $\mathrm{CF}_{3}$ symmetric stretching at $1260 \mathrm{~cm}^{-1}$ occur. $\mathrm{N}-\mathrm{H}$ stretching mode of [BMIM][TFSI] occur at wave number $3521 \mathrm{~cm}^{-1}$ while $\mathrm{CH}_{2}$ stretching mode at $2957 \mathrm{~cm}^{-1}$. For [BMIM] $\left[\mathrm{PF}_{6}\right]$, peaks at $1142 \mathrm{~cm}^{-1}$ in-plane $\mathrm{C}-\mathrm{H}$ bending of imidazolium ring and, C-H vibrations of alkyl chain are at 2948 , $2953 \mathrm{~cm}^{-1}$. The peak at $3165 \mathrm{~cm}^{-1}$ is due to the $\mathrm{C}-\mathrm{H}$ vibration of the cation ring. For [EMIM] $[\mathrm{Cl}]$ and $[\mathrm{BMIM}][\mathrm{Cl}]$ the peaks at $3069.93 \mathrm{~cm}^{-1}$ by stretching of $-\mathrm{OH}$ group and $2860 \mathrm{~cm}^{-1}$ are allocated to $\mathrm{C}-\mathrm{H}$ stretching. The $\mathrm{CH}_{2}$ wagging occurs at $1317 \mathrm{~cm}^{-1}, \mathrm{C}-\mathrm{H}$ stretching at $1371 \mathrm{~cm}^{-1}$, and $\mathrm{C}-\mathrm{O}$ stretching at wave number $1160 \mathrm{~cm}^{-1}$.

The IR spectra of [EMIM] [Br] and [BMIM] $[\mathrm{Br}]$ are quite similar, the strong and sharp peaks were obtained in the range of 1527 (C-O stretching) and $1162.85 \mathrm{~cm}^{-1}\left(\mathrm{CH}_{2}\right.$ stretching) $[17,37]$.

\section{Conclusion}

The major intention of the current work is to provide a straightforward approach and possible information on "imidazolium-based" ionic liquids and their application in energy storage and toxicity removal agents. Thereby, details of quantum chemical descriptors, electrochemical stability, intermolecular interactions, and the Fourier transform infrared (FTIR) spectra were studied. Quantum chemical 
parameters, including HOMO-LUMO energy, energy gap, hardness and softness were studied, giving information on the chemical reaction and stability of IL. The ECWs observed by the HOMOLUMO method with the DFT treatment demonstrated excellent agreement with previously stated literature results $[6,9,15,16,29,37]$. The ILs, [EMIM] [PF6] and [BMIM][PF6] are recognized as the most suitable ionic liquids for energy storage applications. For the removal of heavy metals, the better ILs would be the ones whose complex has a large softness value. Therefore, $[\mathrm{BMIM}][\mathrm{Br}]$ is considered a suitable ionic liquid for shifting toxic wastes, but [BMIM][TFSI] is one of the best. The ionic liquid $[\mathrm{BMIM}]\left[\mathrm{PF}_{6}\right]$ showed a very high interaction energy, which indicates that this IL highly affects the kinetic behavior of organic reactions. It is remarkable to mention that the distinction in HOMO energies between an ion pair and its respective anion is almost precisely equivalent to the interaction energies. The cation-anion coupling tended to cause a decrease in the energies of HOMO in the neutral pairs relative to the free anions. We theoretically investigated IR spectra for imidazolium-based ILs in the range of $400-3500 \mathrm{~cm}^{-1}$, showing better agreement with the reported experimental values $[4-6,11,17,38]$.

\section{Acknowledgments}

The authors would like to acknowledge the research initiation grant (RIG/975/2018) and support of TEQIP-III, M.M.U.T., Gorakhpur (U.P.), India.

\section{References}

[1] J. Nilsson-Hallen, B. Ahlstrom, M. Marczewski, P. Johansson, Front. Chem. 7, 1 (2019).

[2] Z. Lei, B. Chen, Y.M. Koo, D.R. Macfarlane, Chem. Rev. 117, 6633 (2017).

[3] V.C. Ferreira, L. Zanchet, W.F. Monteiro, L.G. da Trindade, M.O. de Souza, R.R.B. Correia, J. Mol. Liq. 328, 115391 (2021).

[4] M. Rezaeian, M. Izadyar, Int. J. Quantum Chem. 119, 1 (2019).

[5] N.A. Noorhisham, D. Amri, A.H. Mohamed, N. Yahaya, N.M. Ahmad, S. Mohamad, S. Kamaruzaman, H. Osman, J. Mol. Liq. 326, 115340 (2021).

[6] P.J. Chengula, T. Pogrebnaya, A. Pogrebnoi, J. Mol. Liq. 299, 112209 (2020).

[7] C. Daghar, N. Issaoui, T. Roisnel, V. Dorcet, H. Marouani, J. Mol. Struct. 1230, 129820 (2021).

[8] A.J. Greer, J. Jacquemin, C. Hardacre, Molecules 25, 5207 (2020).
[9] T.K. Schwietert, V.A. Arszelewska, C. Wang et al., Nat. Mater. 19, 428 (2020).

[10] S.P. Ong, O. Andreussi, Y. Wu, N. Marzari, G. Ceder, Chem. Mater. 23, 2979 (2011).

[11] V.H. Paschoal, L.F.O. Faria, M.C.C. Ribeiro, Chem. Rev. 117, 7053 (2017).

[12] S.K. Singh, A.W. Savoy, J. Mol. Liq. 297, 112038 (2020).

[13] S.M.R. Shoja, M. Abdouss, A.A.M. Beigi, J. Mol. Struct. 1230, 129917 (2021).

[14] L.G. da Trindade, W.A. Christinelli, L. Zanchet, D. Coelho, A.B. Trench, E.M.A. Martini, D.S. Correa, L.H.C. Mattoso, E.C. Pereira, J. Solid State Electrochem. 23, 1109 (2019).

[15] F. Cui, Y. Ni, J. Jiang, L. Ni, Z. Wang, Chem. Eng. Commun. 208, 1580 (2021).

[16] S. Kazemiabnavi, Z. Zhang, K. Thornton, S. Banerjee, J. Phys. Chem. B 120, 5691 (2016).

[17] J. Liu, H. Kim, N.R. Dhumal, H.J. Kim, J. Mol. Liq. 292, 111282 (2019).

[18] M. Wojciechowski, B. Brzostowski, G. Kamieniarz, Acta Phys. Pol. A 127, 407 (2015).

[19] F. Neese, WIREs Comput. Mol. Sci. 2, 73 (2012).

[20] E. Thomas, K.P. Vijayalakshmi, B.K. George, J. Mol. Liq. 276, 721 (2019).

[21] S. Armakovic, S.J. Armakovic, M. Vranes, A. Tot, S. Gadzuric, J. Mol. Liq. 222, 796 (2016).

[22] C.G. Zhan, J.A. Nichols, D.A. Dixon, J. Phys. Chem. A 107, 4184 (2003).

[23] J.L. Gazquez, Theor. Comput. Chem. 5, 135 (1998).

[24] W. Yang, R.G. Parr, Proc. Natl. Acad. Sci. 82, 6723 (1985).

[25] R. Sarkar, T.K. Kundu, J. Chem. Sci. 130, 1 (2018).

[26] C. Lian, H. Liu, C. Li, J. Wu, AIChE J. 65, 804 (2019).

[27] S. Asha, K.P. Vijayalakshmi, B.K. George, Int. J. Quantum Chem. 119, 1 (2019).

[28] K. Fumino, R. Ludwig, J. Mol. Liq. 192, 94 (2014).

[29] A. Hosseinian, M.S. Sadeghi Googheri, J. Mol. Liq. 277, 631 (2019).

[30] M. Miar, A. Shiroudi, K. Pourshamsian, A.R. Oliaey, F. Hatamjafari, J. Chem. Res. 45, 147 (2021). 
[31] R. Vijayalakshmi, R. Anantharaj, A.B. Lakshmi, J. Comput. Chem. 41, 885 (2020).

[32] T.C. Lourenço, L.G. Dias, J.L.F. Da Silva, ACS Appl. Energy Mater. 4, 4444 (2021).

[33] V. Rajadurai, B.L. Anguraj, Environm. Chem. Lett. 19, 1173 (2021).

[34] A. Rajendran, D. Ragupathy, M. Priyadarshini, A. Magesh, P. Jaishankar, N.S. Madhavan, K. Sajitha, S. Balaji, J. Chem. 8, 697 (2011).

[35] M. Fuerhacker, T.M. Haile, D. Kogelnig, A. Stojanovic, B. Keppler, Water Sci. Technol. 65, 1765 (2012).
[36] A. Hosseinian, M.S. Sadeghi Googheri, J. Mol. Liq. 277, 631 (2019).

[37] M.K. Banjare, K. Behera, R. Kurrey, R.K. Banjare, M.L. Satnami, S. Pandey, K.K. Ghosh, Spectrochim. Acta A 199, 376 (2018).

[38] H.F. Hizaddin, R. Anantharaj, M.A. Hashim, J. Mol. Liq. 194, 20 (2014). 